\title{
Editorial
}

\section{Customized Implantat Manufacturing}

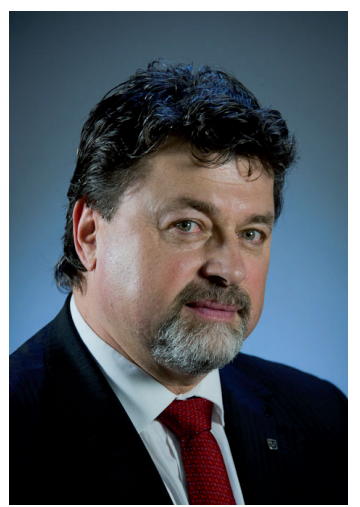

\author{
Dr.h.c. prof. Ing. Jozef Živčák, PhD.
}

Technical University of Košice, Faculty of Mechanical Engineering, Head of the Department of Biomedical Engineering and Measurement, Faculty of Mechanical Engineering, Letná 9, 04200 Košice, Slovak Republic

Jozef Živčák, Dr.h.c. prof. Ing., PhD., is a professor of biomedical engineering at the Technical University in Košice. He was born in 1958. He received his MS and PhD degrees from the Technical University of Košice in 1995. Since 2009 he has been a Doctor Honoris Causa of Uzhorod National University, Ukraine. His research interests include human biomechanics, medical sensors and rehabilitation technology. Today he is head of the Department of Biomedical Engineering and Measurement. Since 1998 he has been an expert witness in machine and electrical technology. He is co-author of more than 280 publications in domestic and foreign journals as well as 9 monographs and 12 books.

The Department of Biomedical Engineering and Measurement is one of the fundamental departments in the framework of the Faculty of Mechanical Engineering, Technical University of Košice. It is a leading workplace in the Slovak biomedical engineering area as well as it is an actively cooperating partner in the Europe and abroad. The main scientific-research space of this Department is focused on the implantology field with a specific targeting on the tailored implants. The second research domain is the platform of metrology, especially parameterisation of the measurement using the invasive and non-invasive methods by means of the state-of-the-art contact and contless processes, such as metrotomography. The third section of our departmental activity is a research and educative employment in the prothetic and orthotic systems arranged in a complex interrelated configuration. The research and application of the tailored implants noticed a distinguished progress at our Department during the last time period. A necessary synergic platform, which is substantial for a successful performing of the above-mentioned activities, was created thanks to a cooperation with the other scientific and professional workplaces, e.g. with the Pavol Jozef Šafárik University in Košice, with the University of Veterinary Medicine and Pharmacy in Košice or with the Central European Institute of Technology in Košice (CEIT KE, Ltd.). Our presented and published scientific-research activities have own requesters and customers. Taking into consideration a fact that the contemporary requirements, concerning the scientific-research work, are more and more demanding with regard to the quality and quantity, as well as with regard to the material, technical, technological and also personal provision, it was necessary to support our research attributes using the project base by means of the internal and foreign research project utilising. These projects are realized under the auspices of the Ministry of Education of the Slovak Republic and our Technical University. The individual workplaces of our Department are equipped with the top worldwide apparatuses or facilities and these our departmental workplaces are cooperating with an analogous top scientific-research professional workplaces abroad. The results of our scientific and research effort are implemented into the realisation phase and just in 


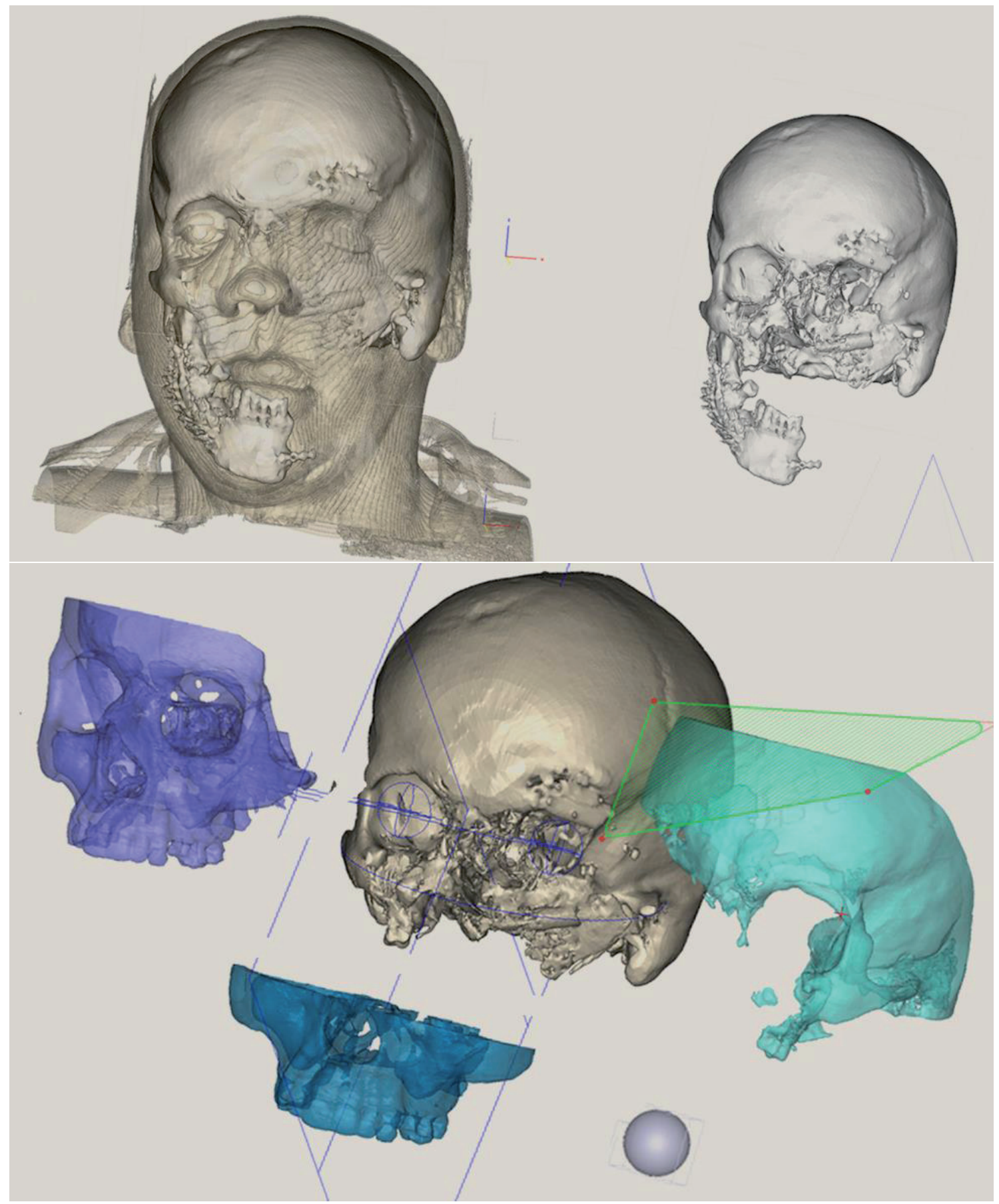

this way there is developed a close cooperation between the educational and business sphere. This kind of cooperation is essential in order to reach the required level of a next scientific orientation of our Department, which is an integrated part for the research potential of the Faculty of Mechanical Engineering, Technical University of Košice. An important component that is situated among our working activities, is the educative process performed in an explicit interdisciplinary space, which is oriented towards the biomedical engineering branch of study. New trends presented in the European and worldwide project challenges are covering also this space of science, which offers new possibilities for a future application of the modern technologies based on the unconventional materials and innovative design. 